\title{
The Digital Transformation Strategy of Hilton During COVID-19
}

\author{
$\mathrm{Xu} \operatorname{Linxi}^{1, *}$ \\ ${ }^{1}$ International Business School, Tianjin University of Finance and Economics, Tianjin 300222, China \\ ${ }^{*}$ Corresponding author. Email: xulinxi@stu.tjufe.edu.cn
}

\begin{abstract}
With the impact of the COVID-19 epidemic, the world economy is in recession and the hotel industry is in a worrying situation. According to the financial and business environment analysis (SWOT model) of Hilton, we find that its operating conditions are poor with a great external threatening. Although Hilton has some digital strategy already, it still needs to build more digital transformation strategy based on data technology. On this basis, measures are proposed for digital transformation strategy for Hilton. After the comprehensive understanding of digital transformation strategy measures, the hotel market could make better strategic adjustments. These results offer a guideline to handle the COIVD-19 issues for other hotels.
\end{abstract}

Keywords: COVID-19, digital transformation, Hilton, SWOT, ratio analysis.

\section{INTRODUCTION}

In the early 2020 s, the outbreak brought the world to a halt and the global economy went into a slump. With countries introducing policies (e.g., city closures and travel restrictions), it had a huge impact on the hotel industry's operations, such as Hilton Worldwide Inc. With the outbreak largely under control, the economy is recovering and the hotel industry is finding ways to save itself. At the beginning of the outbreak, Hilton hotel's occupancy was indeed lower than common times and the figure reflected in financial reports are worse, especially the RevPAR figure. In the post-epidemic era, Hilton have adopted a variety of strategies to deal with the situation (e.g., digital hotel development). Through the digital APP, Hilton could promote the quality of contactless check-in, check-out and develop digital room key service.

\subsection{Literature review}

According to prior literature, digital technology not only highlights its own level of competence, but also constantly strengthens the innovation of hotel applications [1]. Thus, it enhances the competitiveness of the hotel industry and better improves the economic and social benefits of the hotel industry. With China's economy entering a new era, namely the digital network era, digital hotels are gradually showing rapid development in the industry, i.e., digital hotel construction and development strategies are extremely meaningful [1]. As suggested in Ref. [2], it is necessary to turn the variables of the epidemic into opportunities, to innovate and change by means of digitalization, and to tap into the business value of corporate data applications to create change in the midst of change. Because the shift to digital is a disruptive process that requires a rethink of company culture, strategy, operational organization and even external cooperation, companies must be prepared for rapid change and intense competition. Another scholar supposes that corporate digital transformation has a positive role in promoting the performance results, i.e., the learning atmosphere within the company, the common vision and the strengthening of external network cooperation can help digital transformation to product good KPIs [3]. Zhuo proposes that digital transformation encompasses not only technology transformation, but also strategic customer-driven business transformation. This will lead to the successful implementation of a comprehensive digital transformation, which will increase the sales profitability of the company within five years [4]. Gray $P$. selects the case of the healthcare industry as a research object to investigate the issue of consumercentric digital strategy transformation [5]. Three indicators are proposed as key elements to judge digital transformation, namely value chain, value shop and value network, and a multidimensional conceptual model is developed accordingly. The analysis shows 
that the strategic decision areas are along the digitisation of products or services and the digitisation of business models. Only by following these two paths simultaneously can companies finally gain the ability to compete in the growing digital world [5]. K. Schwertner proposed that the ability to digitally reimagine the business is determined by a clear digital strategy supported by leaders in large part who foster a culture able to change and invent the new. Unique to digital transformation, risk taking is becoming a cultural norm as more digitally advanced companies seek new levels of competitive advantage [6]. Alessia C. supposed that the rapid growth of digital technologies and the extraordinary amount of data collected each day are increasingly driving companies to radically transform the business structure through which they create and appropriate value [7]. Simon C. proposed that digital strategy making not only represents a break with the conventions of upfront strategic information systems planning, but reveals a new extreme of emergent strategy making [8].s Specifically, the digital transformation strategy is continuously in the making with no foreseeable end.

\subsection{Gap}

As a matter of fact, there are still some gaps between previous literatures and this paper, as there is the specific situation in the contemporary era, that is COVID-19. Although there has some strategic digital transformation procedures the hotel industry takes, there is still a huge process that hotel such as Hilton needs to operate in more detailed and systematic way. This paper takes Hilton as the subject of this study and examines its corporate strategy in the context of the new crown epidemic. Through a combination of quantitative and qualitative research methods, it explores the possible digital transformation strategy of Hilton in the postepidemic era.

\section{DATA AND METHOD}

\subsection{Data}

Our data collects from Hilton's official website from 2018 to 2020 in financial statements. In addition, our data types include financial data and other data obtained from the internet.

Hilton hotels are Hilton's flagship brand, which is also one of the largest hotel brands in the world. The brand is targeted at both business and leisure travelers with locations in major city centers, near airports, convention centers, and popular vacation destinations around the world. Hilton Hotels \& Resorts participates in Hilton Honors, Hilton's guest loyalty program. Members who book directly through Hilton-owned channels receive exclusive discounts and amenities, e.g., free Wi-Fi, digital check-in, keyless entry, and the ability to use a mobile app to choose specific rooms.

\subsection{Method}

We have used both quantitative and qualitative research methods. The quantitative research method included profit margin, ROCE, current ratio, accounts payable payment period, and interest coverage ratio [9] The qualitative research method used SWOT analysis.

Profit margin=net income/ sales revenue [9], which is one of the commonly used profitability ratios to evaluate the profit degree of a company. It represents what percentage of sales has turned into profits.

ROCE=PBIT/Capital employed [9], which is generally considered to be the primary profitability ratio as it shows how well a business has generated profit from its long-term financing. An increase in ROCE is generally considered to be an improvement.

Current ratio $=$ Current assets/ Current liabilities [9], which considers how well a business can cover the current liabilities with its current assets. It is a common belief that the ideal for this ratio is between 1.5 and 2 to 1 , i.e., a business may comfortably cover its current liabilities should they fall due.

Accounts payable payment period=Trade payables/ cost of sales X 365 days [9]. An increase in the company's payable period could indicate that the company is struggling to pay its debts as they fall due. However, it could simply indicate that the company is taking better advantage of any credit period offered to them.

Interest coverage ratio $=$ operating profit $/$ financial cost [9], which is a debt and profitability ratio used to determine how easily a company can pay interest on its outstanding debt.

SWOT analysis was proposed by professor Andrew of Harvard Business School [10]. This model divides into four parts: the company's strength, weakness, opportunities and threats in order to find a way to improve the strategy of the company in the market. It is a tool for understanding the competitiveness of the Hilton in the business environment, and for identifying the need for digital strategic transformation.

\subsection{Results and discussion}

The analysis will be carried out from two aspects: qualitative analysis and quantitative analysis. Because quantitative analysis is based on the statistical data, this part calculates the financial ratios of Hilton based on the last three years financial statements they posed to the public. This kind of analysis could easily show the trend of the profitability, liquidity and solvency of Hilton. Qualitative analysis is a method to judge the nature, 
characteristics, development and change rules of the analysis object this part of analysis mainly concentrate on the swot analysis to judge the whole performance of Hilton during the COVID-19 period.

\section{QUANTITATIVE AND QUALITATIVE ANALYSIS}

\subsection{Quantitative analysis by financial ratios}

Generally, quantitative research uses statistical methods, based on assumptions or theories, and starts with data collection, i.e., it is usually necessary to collect a large sample of data [11]. Therefore, this analysis applies the indicators described in Sec. 2.2 to carry out the quantitative calculating process. Firstly, the company's profit situation under the COVID-19 is calculated by the profit margin, which is equal to net income/ sales revenue. The data of profit margin from 2018 to 2020 are $8.58 \%, 9.24 \%,-16.6 \%$ respectively. Besides, ROCE could be the primary profitability ratio as it shows how well a business has generated profit from its long-term financing as well. EBIT is Profit before interest and tax. ROCE in 2020 is $-72.52 \%$, which is the revenue in 2020 divided by the total equity in2019 and 2020. Meanwhile, the analysis uses current ratio to consider how well a business can cover the current liabilities with its current assets, which could use it to measure the liquidity as well. The ratios for the past three years are 0.76.0.73.1.73 respectively. With regard to its efficiency under the COVID-19, this analysis takes the Accounts payable payment period as the measurement, which is Trade payables divided by cost of sales multiply 365 days. The period became longer from 44.16 to 86.10 . Finally, when this essay considers solvency of Hilton, it could be calculated through operating profit divided by financial cost, which is interest coverage. the data decreased from 7.78 to 0.38 from 2018 to 2020 .

Table 1. Ratio Analysis

\begin{tabular}{|l|l|l|l|}
\hline Year & 2018 & 2019 & 2020 \\
\hline ROCE & $68.24 \%$ & $2553.62 \%$ & $-72.52 \%$ \\
\hline ROA & $5.41 \%$ & $6.09 \%$ & $-4.51 \%$ \\
\hline EPS & 2.53 & 3.07 & -2.58 \\
\hline PM & $8.58 \%$ & $9.24 \%$ & $-16.60 \%$ \\
\hline current ratio & 0.76 & 0.73 & 1.73 \\
\hline quick ratio & 0.69 & 0.70 & 1.69 \\
\hline $\begin{array}{l}\text { operating CF to } \\
\text { current liabilities }\end{array}$ & 0.49 & 0.50 & 0.27 \\
\hline interest coverage & -1.91 & -2.00 & -3.15 \\
\hline $\begin{array}{l}\text { leverage:assets to } \\
\text { equity }\end{array}$ & 12.61 & 419.59 & 16.08 \\
\hline $\begin{array}{l}\text { leverage:liabilities } \\
\text { to assets }\end{array}$ & 0.92 & 1.00 & 1.06 \\
\hline $\begin{array}{l}\text { leverage:libilities } \\
\text { to equity }\end{array}$ & 11.60 & 418.35 & 17.07 \\
\hline
\end{tabular}

\subsection{Qualitative analysis by SWOT}

As for strength, Hilton is a big hotel company with experienced hotel management group. Hilton has 18 subsidiary brands cover luxury, upper upscale, upscale, upper mid-scale and timeshare hotels. Besides, Hilton has hotels owned or leaded by entities around the world about 6478 with 1019287 rooms on Dec 31, 2020 Secondly, Hilton has large, long-term and stable demands, i.e., it is a big customer for suppliers. Nevertheless, there are many other suppliers can substitute the existing supplier and Hilton has multiple options, which results in low reliance on specific suppliers and forms cost advantages through scale of economics. In addition, Hilton has technology innovations to improve customers experiences and upgrade of business process. For example, Hilton Reservations \& Customer Care (HRCC), which is a Department of Hilton, handles reservations across the entire Hilton portfolio. HRCC covers every major continent and language throughout the world. With a global online services team, Hilton can deal with the problem of customers in time. The last one is about excellent customer loyalty. Hilton has huge brand effects everybody knows Hilton which has some loyal customers. Hilton has an award-winning guest loyalty program called Hilton Honors, which is offered by Hilton Worldwide's top 10 hotel brands, with 34 million members.

Over-dependence on its U.S. home market is Hilton's major weakness. Hilton's headquarters are in the United States. The United States represents a significant portion of our system-wide hotel rooms, 72 percent as of Dec. 31,2020. The current situation, especially in an epidemic environment, makes the company highly vulnerable to market slowdown and intensifying competition in the US. Furthermore, Hilton lacks a flexible business model, which means each hotel has a similar development model and does not have characteristic. Each sub-brand has its own fixed style and characteristics, where the design concept of each hotel is basically the same that lack of personality. As a result, the hotel of Hilton can not perfectly fit the local characteristics to show the local culture.

Under the trend of globalization, the economic interdependence among countries is increasing and the international trade is increasing, which provide opportunities for hotels to develop synergistically in different counties. As a multinational group, Hilton employees with different cultural backgrounds can promote cultural diversity and inclusiveness and facilitate to cultural integration, which is in a line with the idea about globalization. Besides, growing tourism market could also be one of its opportunities nowadays. Moreover, there are still some gaps in the hotel market, e.g., the third- and fourth-tier cities and some emerging markets including popular holiday destinations and 
niche tourism destinations all lacks of the high-end hotels. With the development of the regions, the market demand gradually increases, which is a good opportunity for Hilton to increase the market shares.

Competition from similar hotel-chain will be the threaten, e.g., intercontinental, Marriott, Hyatt, those upper scale hotels. Those middle level hotels also become its competitors for some mid-range brands of Hilton. Contemporarily, the biggest threat of Hilton is COVID-19 which leads to a global recession, especially in real economy. Many countries' government have policies to restrict travel and require people stay at home. The price of hotel rooms and the number of rooms sold are decreased dramatically while the inevitable costs to maintain operations, which led to a sharp drop in revenue or even negative. What's more, COVID-19 affects not only Hilton but also suppliers and partners such as third party owners. If the thirdparty owner of Hilton is affected by COVID-19, it may have financing difficulties and significant income decline, resulting in the inability to maintain its hotel operation in the contract and repay the debt guaranteed by Hilton, which will directly affect Hilton's income and indirectly affect its reputation.

\subsection{Discussion}

This article doing the research for both quantitative and qualitative analysis. In this process, quantitative analysis uses mathematical and financial models to calculate the profit, liability and liquidity of Hilton in the last three years. The qualitative method use large number of words, the information disclosed by Hilton Hotel and the research of the article, making a detailed analysis of the overall internal and external competitive environment and soft power of the enterprise.

With regard to the quantitative part, movements in ROCE are best interpreted by examining profit margins, asset turnover and capital structure leverage in more detail as ROCE is made up of profit margin, asset turnover and capital structure leverage. The data of ROCE shows a decrease trend from 2018 to 2020. Thus, the profitability of Hilton is not good overall, which is a bad performance in profit. As to current ratio, it is a common belief that the ideal for this ratio is between 1.5 and 2 to 1, i.e., a business may comfortably cover its current liabilities should they fall due. However, this data in Hilton in far is below than 1. Meanwhile, the analysis of efficiency is noy perform well. The period became longer from 44.16 to 86.10 . An increase in the company's payable period could indicate that Hilton is struggling to pay its debts as they fall due. Nevertheless, it could simply indicate that the company is taking better advantage of any credit period offered to them.

When the analysis considers the solvency, it increased negatively from 2018 to 2020 . Hence, the interest coverage of Hilton is the negative signal. Hilton's negative interest coverage for these three years indicates that Hilton has made significant losses in these three years and has a weak guarantee of repaying its debts as they fall due. In other words, Hilton's operating costs are high, exceeding the revenue generated by the company's investment. Thus, the financial risk of Hilton is very high.

As to the qualitative part, because this analysis only focuses on the swot analysis, it could be found that the biggest threat of Hilton is covid-19, which leads to a global recession, especially in real economy. According to SWOT analysis, we suppose that Hilton is required to innovate the new digital transformation strategy to adapt for the post-epidemic era, though it already has technology innovations to improve customers experiences and upgrade business process.

\section{CONCLUSION}

In summary, Hilton has bad operation conditions during the COVID-19, where revenue has decreased dramatically as well as the profit and shareholder's equity even became negative. According to the financial index, the profitability, efficiency and solvency are not optimistic. The average daily rate reflects the average price that guests pay per room in a hotel. Average daily rate along with occupancy rate and revenue per available room are both reduced. On this basis, we find that Hilton has a development bottleneck under the existing business model. It is necessary to carry on the enterprise strategic transformation, especially after the COVID-19

In the investigation of relevant materials, it is found that there are indeed transformation behaviors. Hilton already has some information system, which recorded the customers' customs and preference to provide high quality service. Hilton is integrated with advanced levels of information technology in the contemporary situation. For example, Hilton launched digital key platform for customers. Hilton hotels has officially introduced Digital Key, a mobile app, providing members more choice and control over their entire travel experience in order to enhance the quality of experience in Hilton hotels. Technology development is very important in the hotel industry, because it is an evolving modern industry that requires new technologies to save time and work efficiently. For example, Hilton hotels have already installed a single technology platform called OnQ (On-demand Cue), i.e., the properties can function more productively and guests can make better use of their time while in the Hilton hotels [12]. Technology development in the Hilton hotels such as OnQ provides customers personalized services to better adapt to this highly competitive market environment. Especially under COVID-19, the development of digital hotel is 
accelerated. The contactless check-in, check-out and delivery services are attractive to customers in COVID19 , which will play a great role in controlling the spread of the epidemic. Hilton must develop the digital hotels by developing more projects, e.g., digital key, mobile apps, delivery robot and applying them to the daily operation of Hilton. These are all typical manifestations of the digital strategic transformation of enterprises.

The digital transformation is built based on information technology. Digital transformation is about leveraging real-time data and insights to improve responsiveness, quality and accuracy to create greater value for employees and customers. For employees, the digital transformation can greatly reduce unnecessary work, optimize production capacity, and achieve the goal of cost reduction and efficiency increase, e.g., the automation of business processes and the intelligence of professional work. Hotels check-in and check-out, luggage delivery and meals can all done by robots and the facilities in the guest rooms are intelligent. When the customer leaves the room, all the facilities are closed to save energy. Meanwhile, the detection and sensing of the intelligent system can provide a more comfortable environment for the customer. Besides, hotels can improve customer information management system to maintain good communication with customers. Through big data analysis, hotels have a clearer and more comprehensive understanding of customers and the market and can make better strategic adjustments.

The covid-19 not only impact Hilton, but also be a huge challenge for the global hotel industry. These results shed light for Hilton how to make strategy transformation and can be a reference for global hotels to make corresponding strategic adjustments.

\section{REFERENCES}

[1] Mei, Q. (2018). Strategies for the development of China's hotel industry in the context of digitalisation. Journal of Jilin Business and Technology College, 034(004), 60-62.

[2] Feng, J. (2020). Enterprise digital transformation strategies and entry points. Technology and Economic Guide, 28:733(35), 62-63.

[3] Qing, H. (2020). Mechanisms and performance of digital transformation in enterprise. Zhejiang Journal, 241(02), 148-156.

[4] Yan, Z., Jie, H., \& Jun, S. (2020). About the platform strategy for digital transformation of enterprises. Market Watch, 800(12), 37-37.

[5] Gray, P. , Sawy, O. , Asper, G. , \& Thordarson, M. . (2013). Realizing strategic value through centeredge digital transformation in consumer-centric industries. MIS Quarterly Executive, 12(1), 1-17.
[6] Schwertner, K. (2017). Digital transformation of business. Trakia Journal of Sciences, 15(1), 388393.

[7] Correani, A., De Massis, A., Frattini, F., Petruzzelli, A. M., \& Natalicchio, A. (2020). Implementing a digital strategy: Learning from the experience of three digital transformation projects. California Management Review, 62(4), 37-56.

[8] Chanias, S., Myers, M. D., \& Hess, T. (2019). Digital transformation strategy making in predigital organizations: The case of a financial services provider. The Journal of Strategic Information Systems, 28(1), 17-33.

[9] List of Financial Ratios: Advantages \& Disadvantage: Types of Ratios. EDUCBA. (Accessed on April 3, 2021).

[10] Gürel, E., \& Tat, M. (2017). SWOT analysis: a theoretical review. Journal of International Social Research, 10(51).

[11] Bernard, H. R. (1996). Qualitative data, quantitative analysis. CAM Journal, 8(1), 9-11.

[12] Applegate, L. M. , Piccoli, G. , \& Dev, C. . (2008). Hilton hotels: brand differentiation through customer relationship management. Harvard 